\title{
O ambiente da escola - o ambiente na escola: uma discussão sobre a relação escola-natureza em educação infantil
}

\author{
Gleice Azambuja Elali \\ Universidade Federal do Rio Grande do Norte
}

\begin{abstract}
Resumo
Em um momento sócio-histórico no qual ecologia, sustentabilidade e educação ambiental perderam o status de temas emergentes e palavras-de-ordem para se tornarem fatores essenciais à sobrevivência humana, é essencial investigar "o que nossas escolas ensinam em termos de relações pessoa-ambiente". Partindo dessa questão-geradora são abordados aspectos relativos à presença da natureza em estabelecimentos de ensino. Evitando discutir o conteúdo disciplinar ministrado pelos professores, optou-se por abordar tal tema avaliando o ambiente físico de estabelecimentos educativos, sua ocupação e a percepção dos usuários. A pesquisa, utilizando multi-métodos, envolveu vistoria técnica (levantamento e documentação arquitetônica), observação comportamental (traços e mapeamento), questionários, entrevistas e desenhos-temáticos. Como na primeira infância o contato com o ambiente é fundamental, optou-se por estudar escolas para educação infantil (até sete anos) em Natal-RN, tendo se evidenciado a dicotomia entre o discurso e a prática tanto na definição quanto no uso do ambiente escolar.
\end{abstract}

Palavras-chave: educação infantil; ambiente escolar; natureza; relações criança-ambiente; psicologia ambiental

\begin{abstract}
The environment of school - the environment at school: a discussion of the school-nature relationship in the education of children. During a social and historic moment at which ecology, sustainability and environmental education have lost the status of emergent themes and slogans to become essential factors to human life, an important aspect to investigate is "what our schools are teaching to their students in terms of personenvironment relationships". Taking this question as its generating point, this paper dedicates special attention to contact with the nature. Avoiding examination of subjects taught in class, we opted to discuss this theme by evaluating the schools' environment, analyzing their space occupation, and users' perception. The investigation used multi-methods involving: technical inspection (architectural survey and documentation), behavioral observation (traces and mapping), questionnaires, interviews and thematic-drawing. Since the contact with the environment is fundamental to child development, schools for children up to 7 years old in Natal-RN were studied, and a dichotomy between speech and practice was verified in the definition and use of the school environment.
\end{abstract}

Key words: children education; school environment; nature; child-environment relationship; environmental psychology

O ambiente escolar, a vibrante interação de criança, professor, currículo, ambiente, família e comunidade, é um microcosmo do universo: o espaço físico delimita o mundo; o sistema escolar e sua organização revelam a sociedade; as pessoas envolvidas na experiência de aprendizado formam a população. (Taylor \& Vlastos, 1983, s/p)

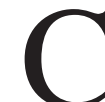

omo um dos principais agentes socializadores, a escola é responsável não apenas pela difusão de conhecimentos, mas pela transmissão dos valores de uma cultura entre gerações (Martin-Baró, 1992). De fato, mais do que em palavras, a educação tem na ação concreta uma de suas principais bases, envolvendo atitudes e comportamentos que, repetindo-se e transformando-se no dia a dia, poderão vir a consolidar-se como prática socialmente aceita. Aliás, a diferença entre o discurso e a prática é considerada um dos motivos que justificam a dificuldade de assimilação/reprodução pelos estudantes de alguns dos “conteúdos” ministrados em classe pelos mestres.

Atuando de modo não-verbal, por sua vez, o meio físico tem impacto direto e simbólico sobre seus ocupantes, facili- 
tando e/ou inibindo comportamentos. Na escola, ele possibilita a decodificação e a aprendizagem até mesmo de normas sociais, comunicando não-verbalmente aos estudantes as intenções e os valores dos professores enquanto adultos que exercem controle sobre o espaço (Horne, 1999; Loureiro, 1990). Assim, tomando-se como exemplo uma sala de aula comum, é possível dizer que os móveis existentes e seu posicionamento informam as expectativas quanto a ocupação do local, percepção que tende a ser confirmada ao longo do tempo a partir da experiência diária, do conhecimento mútuo professor-alunos e das normas institucionais. Cadeiras dispostas em círculo sugerem que ocorrerá uma discussão na qual é esperada a participação de todos; carteiras enfileiradas voltadas para o professor pressupõem aula expositiva; mesas próximas entre si formando blocos maiores indicam a realização de trabalhos em grupos, e assim por diante. Além disso, a disposição da mobília e as condições ambientais da classe (acústica, temperatura, insolação, ventilação, luminosidade) podem refletir-se em fatores tão diversos quanto a sociabilidade dos usuários, seu desempenho acadêmico (Sommer, 1973) e mesmo sua saúde. Nos consultórios pediátricos, por exemplo, são comuns queixas relativas a resfriados, dores de cabeça e garganta, problemas posturais e de coluna, muitas das quais podem estar relacionadas ao ambiente escolar.

Complementando esse quadro, e referindo-se ao contexto sócio-cultural dos centros urbanos brasileiros, Garcia (1996, p. 25-26), argumenta que neles a infância enfrenta um quadro de carências múltiplas, oriundo de tipos de privação: a sócioeconômica, a sócio-afetiva (tanto pela convivência apenas com a família nuclear com poucos filhos, quanto pela desestruturação familiar), a de espaço físico (diminuição do espaço da habitação e do contato com a rua), a de tempo livre (nas classes mais favorecidas seu tempo é tomado por atividades didáticas e formação complementar, e naquelas menos favorecidas pela participação no mercado de trabalho) e a da natureza (contato com elementos naturais como água, terra, plantas e animais).

Neste sentido este texto propõe-se a discutir o que o ambiente físico de nossas escolas está atualmente ensinando a seus alunos, sobretudo no que se refere ao contato com a natureza. Alia-se uma rápida discussão teórica apresentada nos itens iniciais à análise de alguns estabelecimentos para educação infantil situados em Natal-RN, realizada a partir do ponto de vista técnico e da opinião de seus usuários, adultos e crianças.

A opção pelo trabalho com educação infantil justifica-se em função da grande importância do ambiente para o desenvolvimento infantil e da preferência da criança pelo contato com a natureza. Em pesquisas realizadas com crianças e adolescentes entre 5 e 15 anos pertencentes a diversos contextos culturais, Korpela (2002) mostra que, quanto menor a criança, maior sua necessidade declarada por contato direto com áreas externas e ambientes naturais, sendo esse gradativo "afastamento" justificado pela necessidade de aceitação social, com o aumento do interesse por atividades em grupos que ocorram em áreas relativamente fechadas e pelo uso de recursos tecnológicos como alvo ou fonte da atividade lúdica.

\section{Falando nas relações criança-ambiente}

Mais do que base física a partir e por meio da qual a pessoa recebe informações (visuais, táteis, térmicas, auditivas e/ou olfativas-gustativas), o ambiente é um agente continuamente presente na vivência humana. De fato, grande parte do comportamento do indivíduo envolve a interação com o espaço e no espaço, desde atividades simples como alimentar-se e vestir-se, até atividades complexas, como definir um percurso na urbe.

É nesse meio que, ao estender a mão em busca do objeto, ela [a criança] adquire a noção de distância; é nele que a mãe aparece e desaparece, desligada do seu corpo; é ainda nele que exercita o seu domínio, equilibra-se, caminha e corre. (...) É num espaço físico que a criança estabelece a relação com o mundo e com as pessoas (Lima, 1989, p. 13).

A apreensão/compreensão/uso do meio ambiente pelo ser humano e as relações entre a pessoa e o local onde se encontra devem-se tanto às características biológicas da espécie (bípede ereto cujos principais órgãos sensoriais estão voltados para a parte frontal do corpo, dotado de estereoscopia visual e auditiva, e que diferencia direita-esquerda, acima-abaixo, trás-frente, etc.), quanto às características e vivências próprias do indivíduo e do grupo etário e social no qual se insere (Pinheiro \& Elali, 1998).

Embora como objeto de estudo a experiência espacial humana seja evidente desde a década de 70 , é interessante observar que a maioria das teorias da área do desenvolvimento humano ainda hoje mantém tal tema em suas entrelinhas, referindo-se ao mesmo apenas de modo indireto (quando, e se, o fazem). Grandes exceções são as contribuições de Barker (1968) e Bronfenbrenner (1975), respectivamente conhecidas como Psicologia Ecológica e Ecologia do Desenvolvimento Humano que, centradas nas relações humanoambientais, se distanciam consideravelmente das teorias convencionais de desenvolvimento, focadas exclusivamente no indivíduo.

Discutindo o papel do ambiente no desenvolvimento infantil, a literatura na área das relações pessoa-ambiente esclarece que a qualidade de vida (presente e futura) da criança exige a compreensão ecológica de seus comportamentos e a otimização das relações com o ambiente, preocupando-se com a definição de lugares que contribuam para a formação da identidade pessoal, das aptidões e competências individuais (Gilmartín, 1996; Gump, 1974; Ittelson, Proshansky, Rivlin \& Winkel, 1974; Lee, 1977; Lima, 1989; Prescott, 1987; Sommer, 1973; Taylor \& Vlastos, 1983; Weinstein \& David,1987, entre outros). Entre as principais indicações encontram-se:

- valorizar o contexto sócio-cultural em que se encontra o empreendimento, visto haver variação individual e cultural no uso e interpretação do meio ambiente;

- considerar o caráter único de cada empreendimento (perspectiva multi-setting) pois, apesar da experiência huma- 
na ser acumulativa, a prática adequada a um local pode não ser apropriada a outro;

· promover criatividade, variação, participação, exploração e testagem, estimulando a fantasia e a iniciativa;

- oportunizar tanto a interação social quanto a privacidade;

- possibilitar o contato da(s) criança(s) com objetos, lugares e possibilidades de ação, sem a constante intervenção e presença do adulto;

- permitir o engajamento ativo no ambiente, aproveitando e desenvolvendo o senso de natureza inerente à(s) criança(s);

- possibilitar que a(s) criança(s) participe(m) do planejamento do local;

- reconhecer que ambientes planejados para crianças também são ocupados por adultos, cujas necessidades também precisam ser previstas e atendidas.

Assim, dar maior atenção às características sócio-físicas dos ambientes e às relações entre estes e a criança, garantindo a ela oportunidades de contato com espaços variados, tanto construídos pelo homem quanto naturais, é uma maneira de proporcionar à infância condições plenas de desenvolvimento, gerando a consciência de si e do entorno que são provenientes da riqueza experiencial.

Nesse sentido, devido ao seu importante papel na formação infantil, a escola é considerada um dos principais elementos do ambiente social da criança, conceito definido por Lima (1989) como o conjunto de espaços onde ela interage, cujo apego e apropriação são facilitados pela familiaridade.

Referindo-se especificamente à criação/definição do ambiente escolar, Pol e Morales (1991) apontam que a relação entre o momento político-ideológico e as características sociais de um grupo define um modelo de homem ideal para aquele contexto, de modo que (também idealmente) a configuração, a estrutura e o partido estético da edificação escolar deveria refletir tal modelo de homem, as tendências pedagógicas vigentes e a própria sociedade, até mesmo em termos urbanísticos (a localização e as características dos lotes disponíveis, por exemplo)

Em função desse tipo de argumento, pode-se inferir que as bases de cada pedagogia delimitam (implícita ou explicitamente) qualidades físico-ambientais imprescindíveis aos locais que a recebam, relação que pode ser historicamente ilustrada, como nos exemplos a seguir.

Mesmo numa pedagogia tradicional, ao introduzir a lousa em sala de aula, Pestalozzi alterou a concepção daquele espaço, criando um foco de atenção para o qual direciona-se tanto o olhar dos estudantes quanto os esforços didáticos do professor.

Defendendo o jogo, a psicomotricidade e a jardinagem como atividades a serem incentivadas/praticadas na escola, Froebel alertou para a integração escola-natureza e, portanto, para a necessidade desta conter espaços livres utilizáveis pelos estudantes.

A liberdade individual, a autodeterminação infantil e o uso de material didático concreto e lúdico defendidos por
Montessori pediam salas de aula grandes, acomodando um layout flexível (móveis não fixos), a fim de possibilitar: (1) uma disposição dos materiais que facilitasse as escolhas infantis; (2) a ocorrência simultânea e sem interferência mútua de diversas atividades individuais e grupais; (3) a prática de exercícios coletivos em círculos.

Explicitando que o contato da criança com a dinâmica da natureza a estimulava em diversos sentidos, Decroly valorizava o espaço exterior como fonte de saúde e elemento gerador de curiosidade/conhecimento/aprendizado. Para facilitar tal processo a escola deveria dispor de área verde e animais, de modo a possibilitar o acompanhamento da variação das estações do ano e da evolução natural.

Expandindo o conceito de aula para além dos muros da escola, Freinet alterou o conceito tradicional de classe (sala de aula). Além disso, ao incentivar o trabalho em grupos e promover a prática da produção de material didático como atividade discente, ele colocou em evidência as mesas de trabalho maiores e os equipamentos para reprodução de textos (na época, pelo processo tipográfico).

No século XX, o incentivo à maior democratização no uso do espaço proporcionado por algumas das linhas pedagógicas supracitadas foi aliado à consolidação do Movimento Moderno em Arquitetura, fazendo com que a planta-livre ou aberta (sem divisões internas ou adotando divisórias leves) passasse a ser considerada solução adequada para muitos ambientes escolares (Pol \& Morales, 1991; Sommer, 1973).

Apesar da relativa facilidade envolvida na compreensão das relações geradoras dos exemplos históricos acima e suas implicações, atualmente essa decodificação espacial não ocorre de modo tão evidente. Isso provavelmente deve-se tanto à rápida mudança dos métodos psico-pedagógicos, quanto à maior liberalidade em sua adoção, até mesmo com a possibilidade de variação metodológica em uma mesma instituição e turma, permitindo aos professores elegerem a melhor abordagem para cada tema em pauta (o chamado mix-metodológico). Além disso, Oliveira (1998) ressalta a necessidade de enfrentar-se a própria diferença temporal entre pedagogia e arquitetura, o que se reflete no tipo de expectativas e até na durabilidade das ações empreendidas nessas áreas.

(...) o projeto de escola, seja ela qual for, é elaborado prevendo espaços para trabalhos com determinados métodos. E os métodos não duram para sempre. Ficam obsoletos e exigem reciclagem, o que nem sempre acontece, com a mesma velocidade, com o espaço construído. Daí a importância de pensar edifícios que levem em conta a mutabilidade, tão natural nas coisas humanas. (Oliveira, 1998, p. 25)

Complementando tal argumento, França (1994) indica que a diferença entre os ideários pedagógico e arquitetônico impede um melhor diálogo entre essas áreas, pois a primeira preocupa-se exclusivamente com as relações ensino-aprendizagem, enquanto a segunda centra-se na geração de um invólucro construído.

O componente arquitetônico vem sendo visto mais como uma contingência, como uma necessidade de delimitar um 
espaço reservado para a educação, do que como um fator de peso nas relações que vão se estabelecer nesse espaço (França, 1994, p. 98).

Por sua vez, Prescott (1987) amplia tal discussão para a esfera sócio-ambiental ao comentar que os efeitos do ambiente escolar são mediados pela política institucional, de modo que modelos que limitem demasiadamente a criança, inibindo e/ou modelando excessivamente seus comportamentos espontâneos, demonstram simplesmente não suportar as exigências do seu processo de desenvolvimento.

\section{Pensando na área livre das escolas}

Nos últimos anos a atenção com as áreas livres das escolas tem aumentado, sendo a sua quantidade e a qualidade dos cuidados/manutenção e equipamentos associadas à qualidade de vida das crianças (Moore \& Young, 1978; Sanoff \& Sanoff, 1981). Grande parte desse interesse provavelmente deve-se à gradativa redução dos espaços para brincadeira tanto na cidade (pelo adensamento da área urbana e aumento da preocupação com a segurança em seus diversos tipos e níveis), quanto nas residências das famílias. Assim, a existência de áreas livres espaçosas, parte ensolaradas, parte sombreadas, tem assumido cada vez maior importância na delimitação dos ambientes destinados à educação infantil, uma vez que tais locais permitem às crianças desenvolver a psicomotricidade ampla (correr, pular, exercitar-se), participar de jogos ativos e estabelecer um maior contato com a natureza.

Referindo-se a espaços ao ar livre em centros para atendimento de crianças com idade entre 2 e 5 anos situados nos Estados Unidos e Canadá, Moore (1996) define 3 categorias de pátios: mínimos, recomendados e generosos. O primeiro tipo corresponde a uma área aproximada de $7,5 \mathrm{~m}^{2} /$ criança $^{1}$, enquanto no segundo tipo essa relação corresponde a $10 \mathrm{~m}^{2} /$ criança, e no último ela é cerca de $20 \mathrm{~m}^{2} /$ criança.

Utilizando outro critério, ao analisar escolas em Porto Alegre-RS, Fedrizzi (2002) explicita que há muita variação no tamanho de seus pátios, desde os pequenos (com área entre 250,0 e $3500,00 \mathrm{~m}^{2}$, encontrados em estabelecimentos do setor central da cidade), aos grandes (entre 5000,00 e 8600,00 $\mathrm{m}^{2}$, existentes nas escolas de subúrbios, onde a disponibilidade de área ainda é grande).

De fato, independentemente da dimensão final desses espaços, a literatura na área indica que o seu planejamento deveria envolver subdivisão funcional, variação de escalas e materiais, de modo a garantir riqueza de estímulos e possibilidade de realização de múltiplas atividades, em função das diferentes solicitações dos usuários. Entre seus elementos constitutivos, os componentes naturais deveriam ser tratados com atenção especial (Olds, 1989; Weinstein \& David, 1987), a fim de estimular o contato com a natureza em suas várias nuanças, desde vegetação, areia e água, até atividades em horta e cuidados com algum pequeno animal. Plantando, assistindo a planta crescer, colhendo, a criança pode compreender os mecanismos da natureza, reconhecer-se como parte dela e questionar sua própria participação ecológica (Tuan, 1983).
Apesar dessa necessidade evidente, embora no Brasil tais espaços estejam sendo cada vez mais valorizados socialmente, eles ainda são pouco planejados, como constata Fedrizzi (2002), ao relatar que “de modo geral, os pátios escolares não seguem um projeto definido, sendo, na maioria das vezes, considerados apenas como um local onde as crianças ficam quando não estão em sala de aula” (p. 224).

Partindo desse tipo de constatação, que contrasta com o discurso ecologicamente correto atualmente em vigor, tentou-se compreender que lições de "contato com a natureza" estão sendo não-verbalmente ensinadas às crianças nas escolas para educação infantil localizadas em Natal-RN. A que aulas-práticas de ecologia, de relações com a natureza, estão sendo cotidianamente submetidas nossas crianças? Como crianças e adultos usuários desses espaços os percebem? Quais suas necessidades e aspirações com relação aos mesmos? Enfim, o que o ambiente escolar está realmente "comunicando"?

\section{Método}

Partindo das 97 escolas natalenses que oferecem exclusivamente educação infantil, segundo o Censo Escolar 2001 (Secretaria da Educação Cultura e Desporto do Rio Grande do Norte, 2002), definiu-se um processo de aproximações sucessivas, sendo visitadas 41 escolas. Destas, 16 foram detalhadamente vistoriadas e, finalmente, escolhidas cinco para realização dos estudos de caso (foram usados critérios ligados ao tempo de existência do estabelecimento, quantidade de alunos, localização e características de ocupação do lote).

Além da caracterização geral da instituição, a pesquisa (Elali, 2002) preocupou-se com: a proposta projetual em si (ocupação do lote, percentuais de área livre e área permeável, zoneamento de funções); os usos da área livre, isto é, a análise dos fluxos de usuários, dos espaços sociofugidios/ sociopetalados (Hall, 1977), das áreas públicas/ privadas (Newman, 1973) e da diferença de ocupação entre turnos; o comportamento dos usuários durante horários nos quais fossem realizadas atividades menos controladas pelos professores, como entrada/saída da escola e recreio; satisfação/ aspirações dos usuários adultos (pais, professores e funcionários) e crianças.

Na realização do trabalho de campo foram utilizados multimétodos (Sommer \& Sommer, 1997), uma vez que a variedade de questões inerentes ao estudo exigia que para cada grupo de indagações fosse escolhido um modo específico de apreensão da realidade. De um modo geral, os métodos/técnicas de pesquisa utilizados foram divididos em três classes:

- descrição de elementos - envolveu vistoria arquitetônica das escolas através de levantamento e documentação do espaço físico e mobiliário existentes;

- observação comportamental - abrangeu a análise de traços/vestígios de comportamento e mapeamento comportamental centrado no lugar (Sommer \& Sommer, 1997);

abordagem direta dos usuários - composta por: entrevista com pessoas-chave; aplicação de questionários aos 
usuários adultos; realização de desenho-temático (Trinca, 1976) pelas crianças, seguido de entrevista; conversas informais.

Para um relato mais detalhado da metodologia desenvolvida, bem como para acesso aos dados primários que serão apresentados na próxima seção e ao material gráfico (plantas baixas, cortes esquemáticos e fotografias) relativo às escolas estudadas, recomenda-se consulta à tese que gerou este paper (Elali, 2002).

\section{Lendo entrelinhas}

\section{Resultado das vistorias}

$\mathrm{Na}$ maioria das escolas visitadas a área construída (edificação) ocupa entre 50 e $75 \%$ do lote em que estão implantadas. Embora tais percentuais estejam em consonância com o Plano Diretor de Natal / PDN (Prefeitura Municipal de Natal, 1994), que explicita uma ocupação máxima de $80 \%$ do terreno, eles entram em choque tanto com os critérios para obtenção de autorização/reconhecimento dos estabelecimentos de ensino do Conselho Estadual de Educação (Secretaria da Educação Cultura e Desporto do Rio Grande do Norte, 1982), que indica uma ocupação máxima de $1 / 3$ da área existente (ou, no mínimo, uma área livre de $3 \mathrm{~m}^{2}$ /aluno), quanto com as normas do FundEscola (Ministério da Educação e do Desporto, Secretaria de Educação Fundamental, 1993), que sugere o uso de apenas $50 \%$ do lote. Além da defasagem em si (as escolas estudadas não atingem o patamar sugerido por tais normas), estes dados apontam para a existência de uma fiscalização pouco eficaz destes aspectos.

Esses índices se encontram detalhados na Tabela A1, do Apêndice A, para as cinco escolas do estudo de caso, ilustração que é complementada pelas fotos constantes do Apêndice B.

Ainda com referência à quantidade das áreas livres, o total de área livre por escola variou entre $230,00 \mathrm{~m}^{2}$ e 877,00 $\mathrm{m}^{2}$, enquadrando-se na definição de pátio pequeno de Fedrizzi (2002); e sendo até mesmo inferiores às indicações daquela autora. Por outro lado, a densidade-física nesses setores (área livre total dividida pela população infantil presente em um turno) oscilou entre 1,25 e 5,0 m²/criança, ambos inferiores à menor indicação de Moore (1996), supracitada.

Atentando-se, particularmente, para a exigência do PDN com relação à manutenção de $20 \%$ dos lotes como área permeável (o que é justificado pela necessidade de reabastecimento do lençol freático e para evitar enchentes nos períodos mais chuvosos), verifica-se que apenas duas das escolas estudadas respeitam tal limite (mantendo $24 \%$ e $30 \%$ do lote como área não-impermeabilizada), enquanto nas demais, mesmo havendo áreas livres maiores, verifica-se a impermeabilização da maior parte do terreno (há entre 4 e $14,6 \%$ de solo permeável).

Quanto ao tratamento dessa área livre e a valorização de elementos naturais, apenas aproximadamente 30\% das escolas dispõem de setor arborizado, possibilitando que as brincadeiras ocorram em local sombreado e com areia. A maioria dos estabelecimentos tem poucas árvores, em vários casos cercadas por mureta de contenção e localizadas em pátios inteiramente pavimentados e, ainda, cerca de $20 \%$ dos empreendimentos, apesar de manter áreas livres, não dispõe de qualquer árvore ou arbusto de maior porte na área interna do lote, por vezes restringindo a presença do verde a alguns vasos com plantas.

A não-pavimentação dos pisos na maioria das vezes parece ser um incômodo, pois dificulta a manutenção da limpeza em outros setores. Para evitar esse "problema", é comum o revestimento das áreas livres com cerâmica e/ou pedra, ou a execução de piso cimentado, algumas vezes pintado na cor verde, simulando grama, prática que, nos casos estudados, atingiu a paradoxal pavimentação de uma horta, com plantas acondicionadas em vasos de cimento. A não-utilização do gramado, que facilitaria a limpeza e seria uma solução mais ecológica e saudável, inclusive amenizando a temperatura, é justificada pelas instituições devido a sua difícil e dispendiosa manutenção face ao clima local. Em escolas com grande quantidade de área pavimentada, as caixas de areia constituem grandes focos de atração, sobretudo para as crianças menores.

Uma das situações que mais chamou a atenção foi encontrada numa escola cuja área para brincadeiras é totalmente impermeabilizada, não sombreada e sem vegetação, enquanto a sala da diretoria é separada do pátio por um pergolado com muita vegetação, mas de uso/visualização exclusiva da diretora e seus visitantes (uma grande porta/janela de vidro abre-se para a diretoria, enquanto no pátio visualiza-se apenas a parede de fundos que sustenta as pérgolas, revestida com pedras).

Mas a pouca preocupação com um uso ecológico do espaço-escola não se restringe à pequena quantidade de área livre disponível e a quase-ausência de vegetação. Também é evidente a inadequação do tipo da construção ao clima local: em grande parte dos casos as salas de aula estão subdimensionadas frente à quantidade de alunos (densidade física) embora a relação crianças/adultos seja adequada (densidade social), e há dificuldades relacionadas à temperatura dos ambientes (devidas à sua insolação excessiva e pouca captação da ventilação natural) e à propagação de som entre cômodos.

As aberturas, especialmente as janelas, constituem um problema quase generalizado: suas dimensões são insuficientes tanto para ventilação quanto para iluminação das salas de aula, não estão posicionadas de modo a induzir a ventilação-cruzada nos cômodos, e seu peitoril geralmente é alto demais para a estatura das crianças, não permitindo que a maioria das mesmas visualize adequadamente a área externa. Tais inconvenientes, aliados às exigências do clima tropical, implicam a contínua utilização de climatização e iluminação artificiais (em todas as escolas visitadas há ventiladores funcionando continuamente nas salas de aula, e aparelhos de arcondicionado nos setores administrativos) o que, além de reflexo na saúde dos ocupantes, significa aumento no consumo energético. 
Ainda com relação à área interna, especialmente as salas de aula, embora a maioria das instituições visitadas envolva os alunos na ambientação da classe, sobretudo com a colocação de seus trabalhos/atividades nas paredes, em algumas situações a decoração estereotipada (personagens de desenhos animados, trabalhos elaborados por adultos, etc.) chega a ser excessiva, inibindo a necessária apropriação do espaço pelas crianças.

Em termos de ocupação efetiva das áreas livres, nas escolas analisadas os espaços sociopetalados (ou seja, aqueles que atraem as pessoas, tornando-se pontos de convergência de usuários e, portanto, promovendo sua própria ocupação) relacionaram-se a locais sombreados (pátios abertos e sob árvores) e à presença de equipamento/mobiliário (bebedouro, brinquedos e bancos). Por outro lado, entre os espaços sociofugidios (locais dos quais os ocupantes em potencial se afastam) estão: corredores estreitos e escuros, ambientes com insolação direta (o que os torna excessivamente quentes) e locais com grande controle/vigilância institucional (como a diretoria).

Analisando o uso em função das características dos ocupantes verificou-se que:

- As crianças maiores (4 a 7 anos) utilizam ao máximo o espaço disponível, enquanto as menores (2 a 4 anos) mantém-se ao alcance, ao menos visual, de um adulto.

- O espaço exigido por atividades estáticas (que não envolvem muita movimentação) abrange pouco mais que o círculo definido pelos movimentos de tórax e braços do(s) envolvido(s), e ocorrem, preferencialmente, em áreas abertas sombreadas.

- Jogos dinâmicos e populares, que usam bola e envolvem muitas crianças (como o futebol), acontecem, mesmo não existindo locais apropriados para recebê-los.

- Quadras esportivas são valorizadas e muito disputadas, eventualmente podendo tornar-se fonte de comportamento não amistoso entre diversos grupos de ocupantes.

- Em brincadeiras como esconde-esconde, todos os elementos volumosos são aproveitados pelas crianças (tambores de lixo, plantas, vasos, murais) precisando ser locados e fixados com cuidado a fim de evitarem-se acidentes.

- Nas áreas livres os maiores atrativos são as árvores (sobretudo se for possível subir nelas sem perigo), os locais para brincar (especialmente playgrounds e caixas de areia) e onde quer que existam animais como pássaros, tartarugas e pequenos mamíferos (ratos, coelhos, gatos, cachorros), pontos focais da atenção das crianças menores.

\section{Com a palavra os usuários}

As constatações da análise técnica (anterior) transparecem na consulta aos usuários adultos das escolas do estudo de caso (total de 279 pessoas, sendo 145 pais/ responsáveis, 85 professores/assistentes e 49 funcionários). Quando solicitado aos mesmos identificar, entre 30 itens apresentados, os três que consideravam prioritários para a definição de um ambiente escolar adequado à criança, as respostas evidenciaram: aspecto estético (citado por 57,3\% dos respondentes), sala de aula (49,1\%), localização (45,2\%), área livre $(44,1 \%)$, conforto $(41,6 \%)$, dimensão dos cômodos $(34,4 \%)$, tamanho $(27,6 \%)$ e segurança $(14 \%)$.

Complementando tal informação, ao expressarem-se de modo livre sobre o papel do ambiente escolar no desenvolvimento infantil, o discurso de pais e professores ressaltou sua importância em termos de: socialização (apontada por 27,6\% dos mesmos), disponibilidade de mais espaço em complementação ao existente na moradia (22,7\%), consolidação de hábitos/rotinas/limites (16,1\%), mais oportunidades para brincar (14,3\%), aumento da autonomia individual (12,6\%) e do aprendizado (10,9\%), conhecimento de pessoas/lugares diferentes dos familiares (10,9\%), liberdade (6,5\%), possibilidade de maior contato com a natureza $(6,5 \%)$.

É interessante notar que os homens deram maior ênfase aos aspectos socialização, conhecimento de outras pessoas/ lugares e aumento da autonomia individual, como fatores de desenvolvimento, enquanto as mulheres fizeram mais referência ao aprendizado, à disponibilidade de maior quantidade de espaço e à facilitação do contato com a natureza. As professoras (todas do sexo feminino - a figura masculina é quase inexistente nesse nível de escolarização) foram as únicas a citar o favorecimento da psicomotricidade infantil.

A questão do espaço físico assume ainda maior importância ao verificar-se que cerca de $60 \%$ das crianças habita em apartamentos, de maneira que o tempo passado no colégio e as condições do ambiente disponível muitas vezes aparentam tornar-se uma espécie de "válvula-de-escape" na sua vida cotidiana, sendo o único local onde lhes é possível ficar ao ar livre, movimentar-se mais, pegar em areia, sujar-se, assistir plantas crescerem.

$\mathrm{Na}$ análise desses aspectos em função de cada escola do estudo de caso, verificou-se que nem sempre a necessidade de espaço e contato com a natureza correspondeu à maior ou menor disponibilidade de ambientes naturais naquela escola frente as demais, e sim a uma idealização daquele local. Os pais, principalmente, aparentaram "perceber" no ambiente escolar mais atributos do que os nele realmente encontrados. Nesse sentido, eles referiram-se a "jardim com arbustos e flores” ao falar de locais onde há apenas alguns vasos com plantas, denominaram de "piscina" um pequeno tanque, ou "árvore" uma palmeira desenvolvida, mas pouco mais alta que uma criança.

Além disso, os questionários aplicados aos adultos permitiram identificar vários elementos do ambiente físico das escolas considerados "problema”, cuja ênfase recaiu nas deficiências relativas ao conforto ambiental, em termos de temperatura, ventilação, iluminação e controle de ruídos, sobretudo nas salas de aula.

Por sua vez, a opinião das crianças foi coletada a partir do desenho da sala-de-aula e da escola-como-um-todo (ver a Figura C1, no Apêndice C - Alguns desenhos-temáticos das escolas elaborados pelas crianças), acompanhados por descrição do trabalho realizado e entrevista. Participaram da atividade 74 crianças em fase de alfabetização (o último estágio da educação infantil), cuja idade variou entre cinco e sete anos. 
Os elementos naturais se fizeram presentes em cerca de metade dos desenhos de salas-de-aula, a partir de vasos com flores colocados sobre armários e escrivaninhas, árvores desenhadas no quadro (negro ou branco), ou janelas abertas tendo ao fundo uma paisagem com sol, nuvens e vegetação.

Já no desenho da escola-como-um-todo a natureza assumiu o primeiro plano. Em cerca de dois terços dos trabalhos, há árvores, sol e nuvens; enquanto flores, frutos e pássaros estão em aproximadamente um terço deles. Árvores e flores são as grandes vedetes desses desenhos, só superadas pelo Sol. Na representação de algumas das escolas destaca-se a presença de pequenos animais, sobretudo naquelas em que existem mini-zoológicos, também muito valorizados pelas crianças nas entrevistas.

Com relação aos locais da escola mais apreciados pelas crianças, a ênfase na área livre (surgida no parágrafo anterior) se repete, com a citação de parques, playgrounds, quadra descoberta, piscina, mini-zoológico e similares. Além disso, também obtiveram destaque os cômodos especiais, como brinquedoteca, sala de informática e sala de artes, locais de grande atratividade devido a abrigarem atividades diferenciadas e prazerosas.

Demonstrando claramente a necessidade de (e avidez por) contato com a natureza, nos estabelecimentos em que não existiam árvores e jardins, as crianças identificaram a ausência destes como grandes deficiências. Isso é reforçado nas suas sugestões para modificações no ambiente escolar, entre as quais encontram-se plantar e deixar crescer árvores, ter animais na escola, fazer jardim ou quadra esportiva gramados, e construir piscina. Além das rotineiras brincadeiras sobre "só ter recreio o dia inteiro", "trocar a professora” e similares, tais sugestões contiveram indicações sobre adequação do layout (como "mudar banquinhos para melhorar as brincadeiras”, ou "colocar bancos em lugar com sombra”) e informações de caráter institucional ("tomar mais banho de mangueira”, “deixar subir nas árvores”, “deixar pintar a parede”, "ter uma parede para riscar e deixar recados”).

Embora a maioria das crianças não tenha mencionado possuir um "lugar especial” (próprio) na escola, aquelas que se referiram ao tema voltaram a citar as árvores ("lá em cima, porque é quieto e dá pra ver tudo embaixo”) e locais escondidos (nichos). Algumas dessas crianças se prontificaram a mostrar tal "lugar secreto" às auxiliares de pesquisa.

\section{Considerações finais}

O trabalho mostra que, em Natal, o ambiente das escolas para educação infantil não tem sido adequadamente definido/planejado, o que pode dificultar a manutenção da qualidade de vida infantil, uma vez que a área construída apresenta grandes problemas relacionados às condições de conforto (temperatura, ventilação, iluminação e ruídos), e a área livre mostra-se escassa e dotada de poucos recursos naturais.

Em termos da percepção/avaliação desse ambiente pelos usuários, de modo geral há diferença entre pontos de vista de crianças e adultos: as primeiras valorizam as áreas livres e o contato com a natureza, e os segundos preocupam-se com aspectos estéticos e com a sala de aula em si, embora também refiram-se à importância da existência de espaços livres e da presença da natureza na escola.

A necessidade de uma troca mais ativa com o meio natural (sentar na areia, pegar em pequenos animais, molhar-se) surge de modo enfático no discurso e nos desenhos infantis, os quais sugerem que árvores, grama, água, areia e pequenos animais deveriam estar mais presentes no seu dia-a-dia.

Por sua vez, os adultos, sobretudo os pais, embora indiquem a necessidade da natureza estar mais evidente na escola, a condicionam a um controle relativamente severo. Ela deve ser uma natureza "controlada/domesticada": animais presos em gaiolas ou cercados, que não arranhem, biquem ou tenham odores fortes; areia que não suje nem contenha micróbios; árvores que sombreiem mas não soltem folhas ou atraiam insetos, e nas quais as crianças não devem subir por uma questão de segurança. Em outras palavras, o discurso adulto aponta para uma compreensão do ambiente natural como um cenário para a ação infantil e não como um elemento com participação ativa na vida da criança.

Essa dicotomia reflete-se diretamente na organização do ambiente escolar que, embora devesse estar totalmente voltado para o atendimento das necessidades infantis, é diretamente controlado e socialmente construído pelos adultos. Assim, em termos institucionais e familiares, o discurso das administrações das escolas visitadas e de praticamente todos os pais entrevistados corrobora um ideal ecológico, a partir do qual precisa ser incentivada uma maior aproximação entre criança e ambiente, inclusive como modo de promover uma atitude de respeito e cuidado com esse último, o que poderia ser considerado um "primeiro passo" na incorporação da idéia de sustentabilidade. Tal entendimento, no entanto, não tem reflexo direto na realidade ambiental das escolas, uma vez que a definição e o uso do espaço físico disponível nas mesmas nega tal princípio, dificultando o contato criança-natureza e mesmo promovendo um considerável afastamento entre ambos.

Mais uma vez, o ambiente escolar mostra-se um exemplo da diferença entre o discurso e a prática social. Já é hora de nos conscientizarmos desse e de outros paradoxos e começarmos a trabalhar mais efetivamente em direção ao ideal de sustentabilidade sócio-ambiental e à qualidade de vida de nossas crianças...

\section{Referências}

Barker, R. G. (1968). Ecological Psychology: concepts and methods for studying the environment of human behavior. Stanford, Califórnia: Stanford University Press.

Bronfenbrenner, U. (1975). Reality and research in the ecology of human development. Proceedings of the American Philosophical Society, 119, 439469.

Elali, G. A . (2002). Espaços para educação infantil: um quebra-cabeças? Tese de doutorado não-publicada, Universidade de São Paulo, São Paulo.

Fedrizzi, B. A. (2002). Organização em pátios escolares grandes e pequenos. In V. Del Rio, C. R. Duarte \& P. A. Rheingantz (Orgs.), Projeto do lugar: colaboração entre Psicologia, Arquitetura e Urbanismo (pp. 221-230). Rio de Janeiro: Contra Capa Livraria / PROARQ. 
França, L. C. M. (1994). Caos - espaço - educação. São Paulo: Anna Blume. Garcia, E. B. (1996). Ação cultural, espaços lúdicos e brinquedos interativos. In D. S. Miranda (Org.), O parque e a arquitetura: uma proposta lúdica (pp. 15-32). São Paulo: Papirus.

Gilmartín, M. A. (1998). Ambientes escolares. In J. I. Aragonés \& M. Amérigo (Orgs.), Psicología Ambiental (pp. 221-258). Madri: Pirámide.

Gump, P. V. (1974). Big school - small school. In R. H. Moss \& P. Insel (Orgs.), Issues in Social Ecology (pp. 276-285). Palo Alto, Califórnia: National Press.

Hall, E. T. (1977). A dimensão oculta. Rio de Janeiro: Francisco Alves.

Horne, S. (1999). The classroom environment and its effects on the practice of teachers. Tese de doutorado não-publicada, Universidade de Londres, Londres.

Ittelson, W. H., Proshansky, H., Rivlin, L. G., \& Winkel, G. (1974). An introduction to Environmental Psychology. Nova York: Holt, Rinehart \& Winston.

Korpella, K. (2002). Children's environment. In R. B. Bechtel \& A. Churchman (Orgs.), Handbook of Environmental Psychology (2 $2^{\mathrm{a}}$ ed., pp. 364-373). Nova York: Wiley.

Lee, T. (1977). Psicologia e Meio Ambiente. Rio de Janeiro: Zahar.

Lima, M. M. S. (1989). A cidade e a criança. São Paulo: Nobel.

Loureiro, C. (1999). Classe, controle, encontro: o espaço escolar. Tese de doutorado não-publicada, Universidade de São Paulo, São Paulo.

Martin-Baró, I. (1992). Acción y ideología - Psicología Social desde Centroamérica. San Salvador: UCA Editores.

Ministério da Educação e do Desporto, Secretaria de Educação Fundamental. (1993). Programa FundEscola. Brasília: Autor.

Moore, G. T. (1996). Determining overall space needs in campus child care centers. Campus Child Care News, 11(1), 3-6.

Moore, R., \& Young, D. (1978). Childhood outdoors: toward a social ecology of the landscape. In I. Altman \& J. Wohlwill (Orgs.), Children and the environment (pp. 83-127). Nova York: Plenum.
Olds, A. (1989). Psychological and physiological harmony in child care center design. Children's Environments Quarterly, 6(4), 184-223.

Oliveira, N. C. (1998). Evolução e flexibilidade da arquitetura escolar. In Fundação para o Desenvolvimento da Educação (Org.), Arquitetura escolar e política educacional: os programas na atual administração do Estado (pp. 11-25). São Paulo: Autor.

Pinheiro, J. Q. \& Elali, G. A. (1998). Comportamento sócio-espacial humano Manuscrito não-publicado, Universidade Federal do Rio Grande do Norte, Natal.

Pol, E., \& Morales, M. (1991). El entorno escolar desde la Psicología Ambiental. In F. Jiménez-Burillo \& J. I. Aragonés. Introducción a la Psicología Ambiental (pp. 283-303). Madri: Alianza Editorial.

Prefeitura Municipal de Natal. (1994). Plano Diretor de Natal. Natal: Autor.

Prescott, E. (1987). The environment as organizer of intent in child-care. In C. Weinstein \& T. David (Orgs.), Spaces for children: the built environment and child development (pp. 73-88). Nova York: Plenum.

Sanoff, H., \& Sanoff, J. (1981). Learning environments for children: a developmental approach to shaping activity areas. Washington, DC: Humanics.

Secretaria da Educação Cultura e Desporto do Rio Grande do Norte. (2002). Censo Escolar 2001. Natal: Autor.

Sommer, R. (1973). Espaço Pessoal. São Paulo: EDUSP.

Sommer, B. B. \& Sommer, R. (1997). A practical guide to behavioral research: tools and techniques. Nova York: Oxford University Press.

Taylor, A. P., \& Vlastos, G. (1983). School Zone: learning environments for children. Corales, New Mexico: School Zone.

Trinca, W. (1976). A investigação clínica da personalidade: o desenho livre como estímulo de apercepção temática. Belo Horizonte: Interlivros.

Tuan, Yi-fu (1983). Espaço \& Lugar: a perspectiva da experiência. São Paulo: Difel.

Weinstein, C. S., \& David, T. G. (1987). Spaces for children: The built environment and child development. Nova York: Plenum.

1 A indicação original, de 80 square feet/child, foi transformada para o sistema métrico decimal.

Gleice Azambuja Elali, doutora em Arquitetura e Urbanismo, Universidade de São Paulo, é professora adjunta nos Programas de Pós-graduação de Psicologia e de Arquitetura e Urbanismo, e pesquisadora no Grupo de Estudos Inter-Ações Pessoa-Ambiente, Universidade Federal do Rio Grande do Norte. Endereço para correspondência: Av. Getúlio Vargas, 782/1101; Natal, RN; 59012-360. Tel.: (84) 202-4270. E-mail: mgelali@terra.com.br 
Apêndice A

Tabela A1

Dados gerais das cinco escolas do estudo de caso

\begin{tabular}{|c|c|c|c|c|c|c|}
\hline \multirow{2}{*}{\multicolumn{2}{|c|}{ ITEM ANALISADO }} & \multicolumn{5}{|c|}{ ESCOLAS } \\
\hline & & $\mathbf{A}$ & B & $\mathbf{C}$ & D & $\mathbf{E}$ \\
\hline \multicolumn{2}{|l|}{ Área lote (m2) } & $2.250,00$ & $1.220,00$ & $1.547,00$ & $1.840,00$ & $1.520,00$ \\
\hline \multicolumn{2}{|l|}{ Área construída (m2) } & $1.375,00$ & 858,00 & 840,00 & $1.528,00$ & 890,00 \\
\hline \multicolumn{2}{|c|}{$\begin{array}{l}\text { Índice utilização (área construída / área } \\
\text { lote) }\end{array}$} & 0.61 & 0.70 & 0.54 & 0.85 & 0.58 \\
\hline \multicolumn{2}{|c|}{$\begin{array}{l}\text { Taxa de ocupação (\%) } \\
\text { (projeção sobre lote / área do lote) }\end{array}$} & 61 & 67,5 & 54,2 & 77,5 & 58,5 \\
\hline \multirow{2}{*}{ Área livre } & Área (m2) & 877,00 & 396,00 & 708,00 & 230,00 & 646,00 \\
\hline & $\%$ do total & 39,0 & 32,5 & 45,8 & 12,5 & 42,5 \\
\hline \multirow[t]{2}{*}{ Permeabilização } & Área (m2) & 540,00 & 134,00 & 464,15 & 73,65 & 222,00 \\
\hline & $\%$ do total & 24,0 & 11,0 & 30,0 & 4,0 & 14,6 \\
\hline Número de alunos & (total) & 350 & 520 & 162 & 450 & 180 \\
\hline $\begin{array}{l}\text { Densidade física } \\
(\mathrm{m} 2 / \text { criança })\end{array}$ & $\begin{array}{l}\text { Sala aula } \\
\text { (Média) }\end{array}$ & 1,45 & 1,18 & 2,37 & 1,12 & 1,0 \\
\hline \multirow{2}{*}{$\begin{array}{l}\text { (Área / número alunos } \\
\text { simultâneos no turno) }\end{array}$} & Pátio coberto & 1,04 & 0,3 & 1,78 & 1,47 & 0,56 \\
\hline & Área livre & 5,0 & 1,37 & 3,8 & 1,25 & 4,3 \\
\hline
\end{tabular}




\section{Apêndice B}

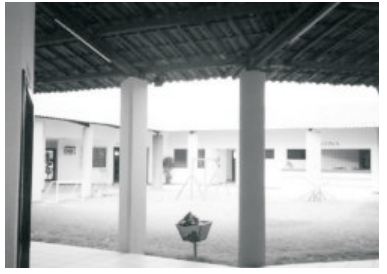

Pátio gramado sem sombras

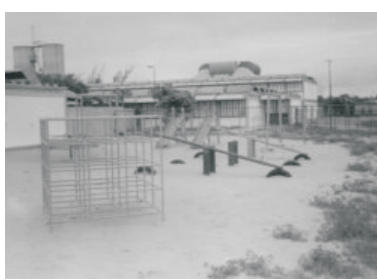

Pátio em areia mas sem sombras

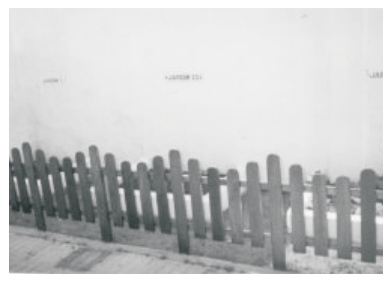

Mini-horta: delimitada por cerca baixa e com canteiros internos

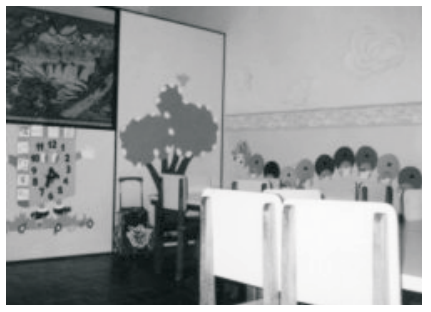

Sala de aula muito decorada - pouco espaço para apropriação pela criança

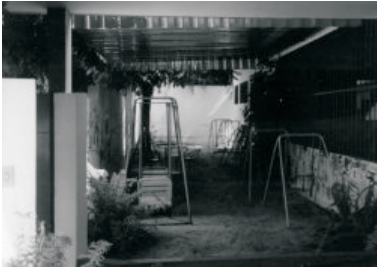

Pátio restrito à recuo lateral: pérgolas protegem mas escurecem

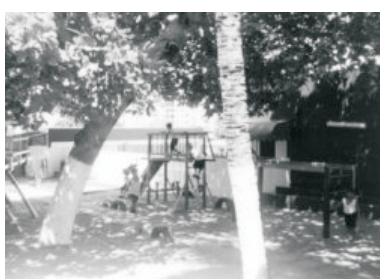

Pátio em areia e com sombreamento

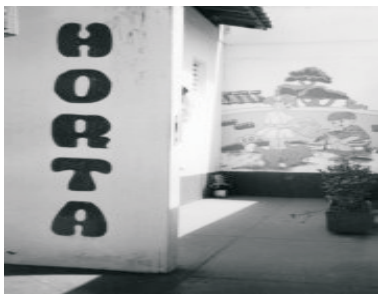

Mini-horta: piso pavimentado e pintado, plantas em vasos

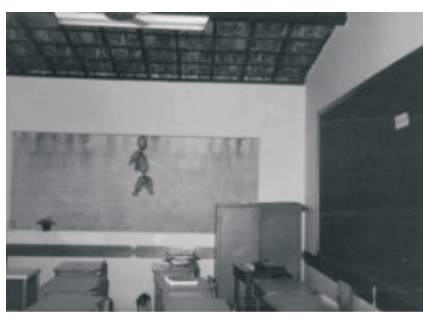

Sala de aula escura

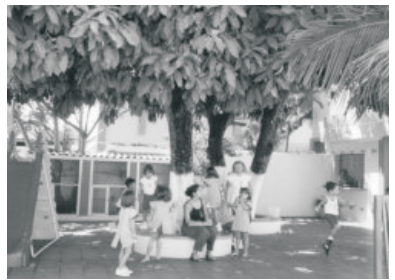

Pátio sombreado mas pavimentado, árvore contida por mureta, mini-zoo

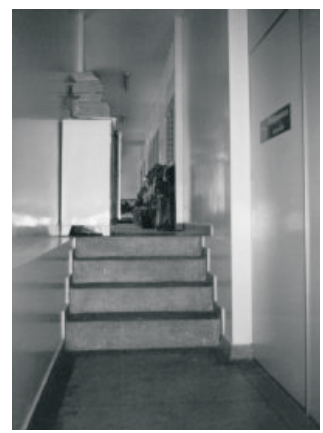

Escada interna com degraus muito altos e hall parcialmente obstruído

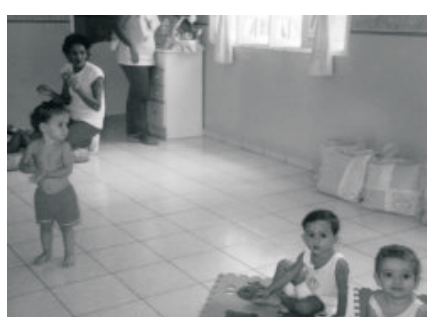

Janela com peitoril alto para a estatura das crianças

(Fonte: Elali, 2002 - originais coloridos).

Figura B1. Fotos de algumas escolas visitadas. 


\section{Apêndice C}

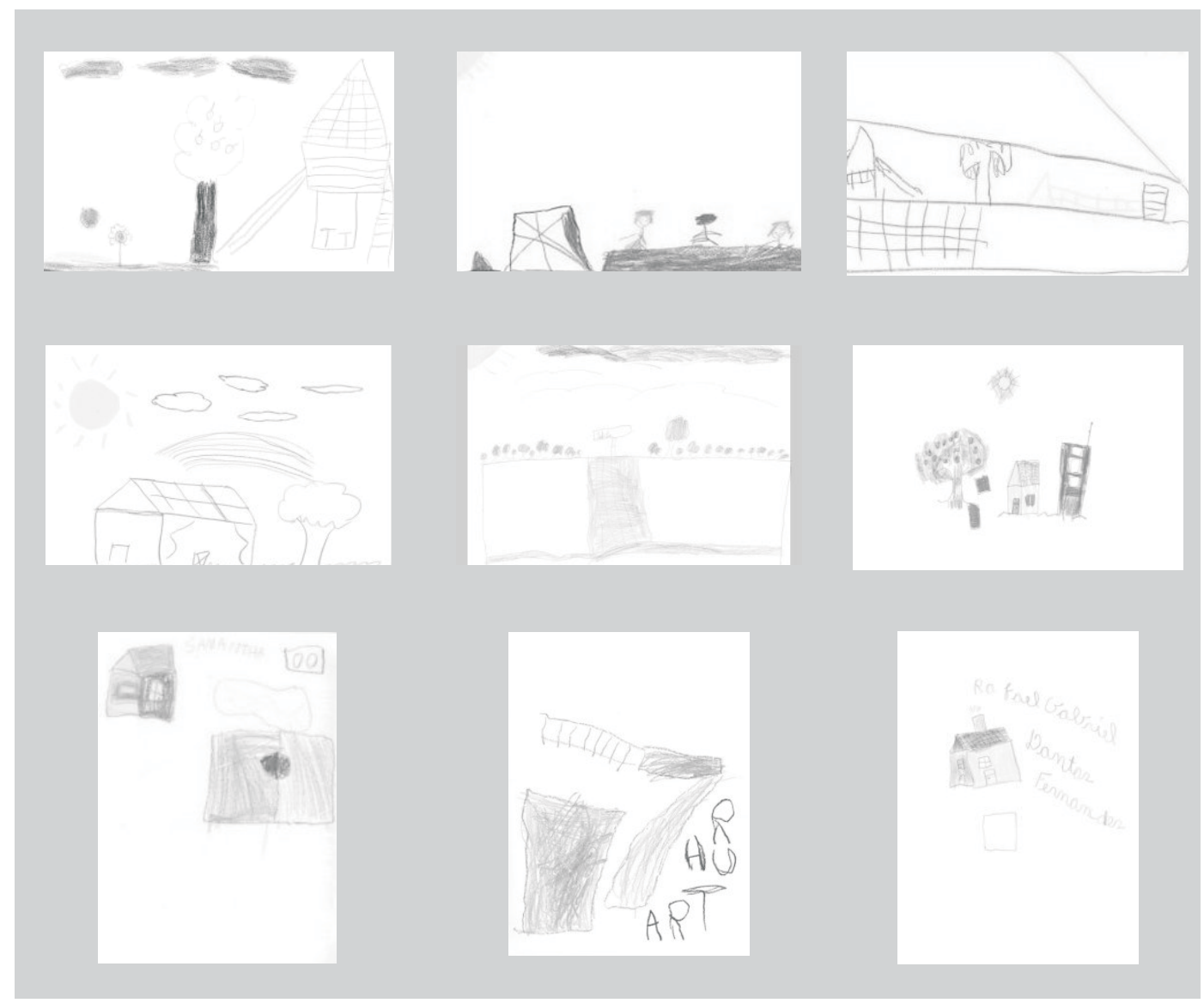

Fonte: Elali, 2002 (originais coloridos).

Figura C1. Alguns desenhos-temáticos das escolas elaborados pelas crianças. 